\title{
Recording Process of Visual Archive for Cultural Heritage
}

\author{
Byung-Eun Park and Dae-Geun Lim \\ Department of Global Culture and Contents, Graduate School of Hankuk University \\ of Foreign Studies, Korea \\ laramagic@naver.com,rooot@hufs.ac.kr
}

\begin{abstract}
This paper discussed the recording process and context of the visual archive which records the cultural heritage in video. The cultural heritage record has a value for permanent preservation by being a core material for national and cultural identity of a country, and has its own value as information. Visual archive is one of the recording methods for cultural heritage along with the static image like a picture and the reports documenting contents in writing. Visual archive is useful for the efficient delivery of information with visual images and audio system. Context should be considered to distinguish between data and information more clearly in the process of production and utilization of information. The transformation process of data to information was studied by considering context during the process of recording cultural heritage in images. As a result, we expect that cultural heritage is classified by knowledge information and becomes a foundation used actively for creating cultural contents.
\end{abstract}

Keywords: Context, Visual Archive, Cultural heritage

\section{Necessity of Visual Archive for Cultural Heritage}

Every art connects us emotionally to a life, actions and corresponding problems which would have been strange without those works by giving us the proxy experience for different realities we did not experience. Confronting new thoughts and experiences, we find ourselves responding to new situations, and become to form new attitudes. You can say visual media established itself as major media connecting the past and actual problems and letting us think and respond by getting us to have indirect experiences more than any other art in the $21^{\text {st }}$ century. Now visual media by its existence captivates the audience and viewers.

This is because information acquirement of a human being is made by visual system like images, signs and symbols as well as audio system like human language, natural language and music. Acquired information is stored in our memory device, and if other information is entered, new information structure is made through recombination of memory. The combination of visual elements like images and audio information like spoken language influences our memory device and works more clearly on the recombination of information. What is important here is that stimulation status and level for visual or audio system is related to the efficient delivery of information.

A human being has a desire to share his or her experiences with others. Even though variety of methods could be used at this time, the most frequently used ones are language or 
writing. However, expression methods like language or writing have limits in their own way. What we experienced are situations, scenes and incidents, not language, in fact. We are expressing in language or writing to let others know them. But only language and writing remain after dynamic elements and scenic aspects are all abstracted from the incidents made during this process. That's why the importance of visual record is increasing now, compared to the past when we relied mainly on literal record.

Visual archive is one of the recording methods for cultural heritage along with the static image like a picture and the reports documenting contents in writing. Having visual image as well as audio system like background music, narrations and direct sounds, visual archive which records through visual recording devices is useful for the efficient delivery of information. Recording cultural assets like cultural heritage through the medium of image is excellent in the efficiency of information delivery and the effectiveness of leaving good memories. Recording the site of cultural heritage is essential since it would be a great help to restoring the accurate original form when damaged.

As a community outcome of national level, cultural heritage has the highest spiritual value representing the identity of a nation. It is the cultural asset involving the historicity, artistry and scientific value of that nation. Having this definition of cultural heritage, the cultural heritage record becomes a core material for national and cultural identity of a country. Thus it has a value for permanent preservation and its own value as information. Therefore, the cultural heritage record has the following characteristics different from general record.

First, the cultural heritage record is a core material for the national and cultural identity. It is imperative for understanding history, tradition and culture right, and has a value for permanent preservation since it becomes a study material for the scholars of next generation. It is important since it becomes the source material needed to newly examine the unknown history and form correct understanding about culture and cultural community. Narrowing distance between countries due to advances in technologies and information communications has an important value for maintaining and succeeding cultural identity of each country. Second, it is the essential material for restoring and reproducing the original form of cultural heritage. Cultural heritage might become a subject of loss due to man-made or natural disaster at any time. It carries a role of record restoring and reproducing the damaged original form as much as possible. Third, it is a source material for cultural creativity. It is a good cultural tourism asset for foreigners and becomes a foundation of creating new knowledge for us. Besides national economic power, intangible asset is now becoming the source for determining the wealth of a country. Fourth, it is the core material for the increase of national image and the development of cultural industry. Developing cultural products with subjects of cultural heritage and traditional culture brings an added value of raising national image in addition to the visible advantage of creating economic benefits. Also, it becomes the resource of applied cultural industry in addition to the tourism element. Fifth, it is the source material for realizing cultural welfare. It realizes cultural welfare for people demanding cultural heritage and variety of services, and plays a role of raising civic consciousness by providing educational opportunities. Sixth, it is a core material for green and future industries. The cultural heritage record in digital ages of social networks, smart mobile services, smart TV and big data becomes the base material for the foundation of future industries like green industry.

Record for cultural heritage which is a foundation of a country is accumulated as a cultural asset with critical value. And it is now possible to maximize the effect of a record according to the medium and methods of recording cultural heritage. 


\section{Production of Visual Archive for the Excavation Process of Seoul City Hall Cultural Assets}

All materials left by the human race become the subjects of archeological study. In archeology, not only expensive materials like golden relics, treasure boxes and weapons, but also small piece of broken bowl, a dish or a rock is treated preciously. They include all natural objects of human relationships like animal bones and botanical seeds in addition to the devices made directly by a human being. Through this, we can examine the climate and environment in which a human being had a life.

Unlike other areas, archeology has a distinctive process of material gathering. In other words, the process of directly gathering archeological materials such as digging out and gathering relics as well as studying the ruins made by human activities. We should accurately determine the location, associated relationship, and stratigraphic sequence of relics to find the meaning of the relics. It means that the site for human residence, fire hole or soil becomes critical information. Therefore, the most critical start in archeology is the excavation.

Construction site for the new Seoul City Hall is at the address of 31, Taepyungro $1 \mathrm{Ga}$, Junggu, Seoul. Before building the new Seoul City Hall, relic excavation was started, knowing that there were Joseon dynasty relics buried under the ground. One hundred and ten days of excavation was made from June 11 to December 10 of 2009 here.

The following is the history of Seoul City Hall. The first 'Gyungseong (old name of Seoul) Ministry Hall' was built as a Japanese consulate under Joseon government. The construction of Japanese consulate was started in July, 1895 and finished in January, 1897. Its use was changed to the 'Esacheong' after the Protectorate Treaty between Korea and Japan in 1905. It became the 'Gyungseong Ministry Hall' with the National Humiliation of Korea in 1910.

'Gyungseong Ministry Hall' was geographically in the capital city, located north of Deoksugung Palace. It had the best location in the overall city structure aspect of Seoul. Designed as a building with four floors above ground and two rooftop floors in March, 1924, it was complete in construction two years later in September, 1926.

After the construction plan for new Seoul City Hall was decided, everything was removed except the main building which had been named as the registered cultural asset number 52 . Breaking down the parking lot building next to the right of the main building, excavating, dismantling and moving work of cultural assets was processed.

There was a 'Gungisi' in the past Joseon Dynasty at the site of Seoul City Hall. 'Gungisi' was a government office controlling the manufacturing of weapons in the Joseon Dynasty, and has enough reasons for excavating, dismantling and moving cultural assets. This 'Gungisi' was established with a name of 'Gungigam', and renamed as 'Gungisi' in 1362, the $11^{\text {th }}$ year of King Gongminwang. It had appendix facilities where lots of explosives, bows and canons were manufactured.

Historical records having 'Gungisi' are 'History of Korea', 'Gyeonggukdaejeon' and 'Donggukyeojibigo'. 'The Annals of the Joseon Dynasty' which is one of the representing historical records has 693 records of 'Gungisi'.

Excavation findings at the new Seoul City Hall site were the shore protection stonework, twenty one building sites, two wells and nine walls. Excavated relics were ceramics, roof tiles, metals and wooden vessels. 


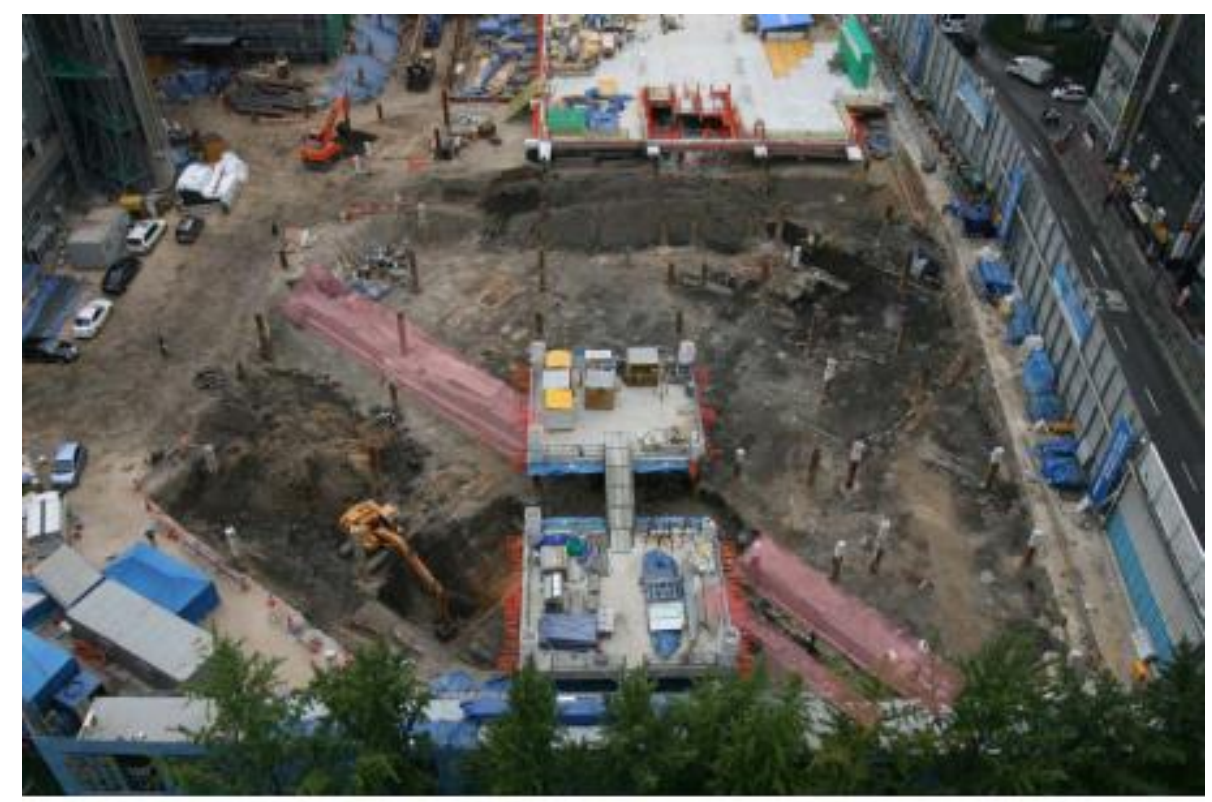

\section{Figure 1. Aerial Photograph with Complete View of the Investigated Area}

Archeology lets us see the 'big picture' of ancient history. If we want to know where we are heading, we need to chase the past track to see where we are from. This is why excavating and restoring cultural assets through archeology is important.

\section{(1) Planning Process}

Appreciating the necessity of visual archive during the process of excavating, dismantling and moving cultural assets, the 'Hangang Institute of Cultural Assets' which is an institute excavating cultural assets and the 'Institute of Historical Culture and Contents' pursued the visual archive from the excavating process of cultural assets. Although there were visual archives of researchers inside the 'Hangang Institute of Cultural Assets', there were no visual archives of the expert photographer. Thus you can say that getting closer to more specialized visual archive is a big accomplishment.

As image work was started, continuous communications between the photographer and researcher were made. The researcher gave the photographer the concept of archeology, relics, remains and knowledge about the whole process of excavation. The photographer instructed the researcher about usefulness and characteristics of the image work. So the photographer could take pictures on the parts the researcher wanted to record, and could have detailed photographing as he learned the specialized contents about excavating knowledge of cultural assets.

\section{(2) Photographing Process}

The excavating investigation was started on June 11, 2009, and was proceeded for 110 days of site investigation days until December 10, 2009. Excavating work was proceeded professionally with the map, advisors, investigators and assistants to investigators. Excavating with a focus on modern remains, the shore protection stonework, twenty one building sites, two wells, nine walls and designated piles were unearthed.

During this process of excavating many important relics, feeling keenly about the necessity of visual archive, the 'Hangang Institute of Cultural Assets' asked the 'Institute of Historical 
Culture and Contents' for the visual archive. So the visual recording work was started from early November.

I photographed the whole process of excavating cultural assets by myself in the early stage. Photographing was started from November which was later than the starting time of the excavating investigation. It was photographed with SONY PD-170 6mm for 3 4 days a week from 8 o'clock in the morning when excavating work was started to 5 o'clock in the afternoon.

By seeing lots of gunpowder weapons excavated by this investigation, we could identify the 'Gungisi' site of early Joseon Dynasty which only existed in documents. Especially, 'Bulranggijapo', which was a child cannon attached to 'Bulranggi' and loaded cannon balls and gunpowder, brought huge interest with reports on several newscasts and newspapers for the first identified case during the excavating investigation period.

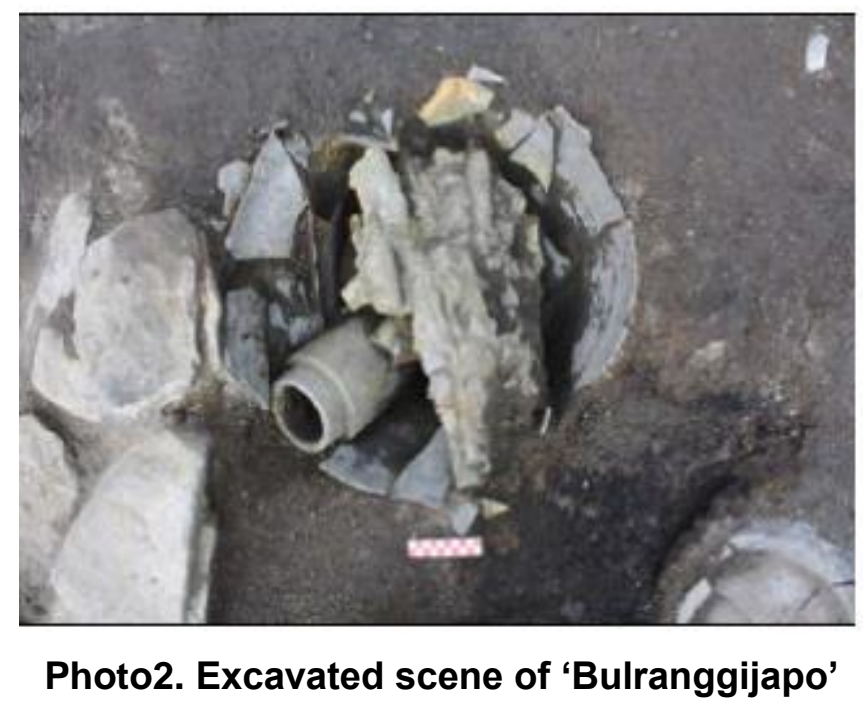

If photographing work was made simultaneously with the start of excavating work, we could have vividly photographed the process of excavating and verifying the important relics like 'Bulranggijapo' at the site.

We are unable to accomplish anything if we just maintain the tapes after photographing is over like now. Even though there is an environmental problem of the institute where free viewing of the visual archive tapes are not possible, fragmentary record will make it remain as a picture in the report. Thus we should produce the final edited film of 15 20 minutes. This final edition would include the subtitles informing the detailed process, the editing effects reproducing the screen efficiently, the background music and voice actor's narrations elevating the process of the film. This would become the final outcome of visual archive, and is the way to effectively deliver the process of excavating cultural assets to the experts and others who do not know archeology.

This final edition could be produced in various forms. We could produce it in the documentary format with a story for the whole excavating process. Suggesting one more to this, we might edit the whole to have a structure like a book. We would have five separated parts of ten minutes. For instance, we would have the planning process, excavation, dismantlement, movement, preservation and dispatch of excavated cultural assets to a museum. Thus general archive of 50 60 minutes is complete by showing each of the detailed process of ten minutes. 


\section{Visual Archive and Context Embodiment}

The record is comprised of the content, context and structure. Individual record which has contents of activities in certain structure is tied with other records in the physical structure called filing system, and would become to be able to deliver the evidence and context of functions and activities again

Individual record produced by the specific activities and needs is gathered to create a file with the same issue, and the bunch of records with the same functions are gathered to form a record series and be a part of the bigger record group of same formation. The record is comprised of the content, context and structure as the individual unit, and at the same time is hierarchically classified as the item, file, series and group at the gathering level.

The context becomes important after the content when producing the visual archive, and we will examine further the context of visual archive production. Surrounding a certain subject, the context might be defined as every element which gives the meaning or effect to that subject. You should consider the context during the production and utilization process of information if you want to distinguish data from information. Information could not exist without the context. The context is not only related with the environment of data, but also means where it came from, why it should be communicated, how it was arranged and what the attitude and environment of the understood person was. Since the meaning and value of information is different depending on its user and situation, the context of producing and using information is important. When producing visual archive, the context of photographed subject like the location, environment and overall view becomes an important element in addition to the subject itself.

Table 1. CONTEXT needed at the visual archive production

\begin{tabular}{|c|c|c|}
\hline $\begin{array}{l}\text { Photograph } \\
\text { ing Subject }\end{array}$ & $\begin{array}{c}\text { Classification of } \\
\text { Photographing Subject }\end{array}$ & Context \\
\hline Things & $\begin{array}{l}\text { remains, device, goods, } \\
\text { work, clothing, specialty, } \\
\text { food }\end{array}$ & $\begin{array}{l}\text { location of a thing, the whole and } \\
\text { details, key characteristics of the } \\
\text { subject }\end{array}$ \\
\hline Person & $\begin{array}{l}\text { interview of the subject } \\
\text { person, acting figure }\end{array}$ & Environment of the person located \\
\hline Relics & $\begin{array}{l}\text { building, tomb, ancient } \\
\text { tomb, scattered relic sites, } \\
\text { site, tower, monument, } \\
\text { literature }\end{array}$ & $\begin{array}{l}\text { location of the relics, various sides, key } \\
\text { characteristics }\end{array}$ \\
\hline View & $\begin{array}{l}\text { the whole town view, } \\
\text { nature view }\end{array}$ & the whole view \\
\hline Events & $\begin{array}{l}\text { ritual, festival, ceremony, } \\
\text { athletic meet, play, } \\
\text { performance, display }\end{array}$ & $\begin{array}{l}\text { appearance of event participants, } \\
\text { program contents, theme of the subject }\end{array}$ \\
\hline
\end{tabular}

When producing the visual archive of cultural heritage, key subjects are classified largely as things, person, relics, view and events. Here, things are classified as remains, device, goods, 
work, clothing, specialty and food. You should not miss the location of a thing, the overall and detailed view of the thing and key characteristics of it when you photograph a thing. For photographing a person, you will mainly have the interviewing or acting figure of the person along with the surrounding environment. Showing the person's work more clearly by including the working view in the work-related place is important like interviewing the person in the library or study if the person is a scholar. Relics include the building, tomb, ancient tomb, scattered relic sites, site, tower, monument, literature, and explains the background of relics by showing the relic place broadly and notifying the location of it. The view showing the town and nature view is the same. Events include the ritual, festival, ceremony, athletic meet, play, performance and display, and does not lose the context by having the contents or theme of the program and the appearance of event participants shown in one view.

Visual archive needs the context of visual archive production for not just remaining as data and becoming information.

How do we realize the visual context to have a role of information, not just being stored as data?

If we examine the photographing subject in paragraph 3, we should photograph the thing with the accurate focus, undistorted standard and the structure of connecting the whole to the detailed parts on telephotographic condition. We should also maximize the key characteristics of a subject through depth control and zoom in-out. For the case of a person, photographing should be made to have his or her natural look harmonized with surrounding environment. With narrow depth, it should also be adjusted to make the person stand out than surrounding environment. However, when we photograph the activity of a person, we should select the place having similar characteristics with the activity to have no discrepance. When we photograph the relics, we should have a stable angle for no distortion, and various sides like front, side and back should be seen. Also, we should show where the relic is located by showing the place and surrounding environment. Scenery like the whole town view and nature view is sensitive to the condition of weather and light control. Therefore, photographing should be made considering this. Since there are many instances when the subject needs wider angle of view than relics and events, we should use the wide-angle lens or add a panoramic method. Events like festival and ceremony should be sequentially photographed at the right order to show contents of the whole event clearly. Since the appearances and activities of participants must stand out, we should not miss the most prominent part.

\section{Conclusion}

Recording type of archeology in Korea with reports as major methods could revitalize the vivid sense of realism with the rising importance of visual archive. The fact that photos attached to the report are not separate in pieces to be understood by fitting them together, but they can deliver the overall onsite view in various angles correctly was the key characteristic of visual archive. The process of excavating, dismantling and moving cultural assets at the construction site of new Seoul City Hall was made. Agreeing to make a visual archive for the sequential process, each institute had the visual work from November, 2009 to March, 2010.

Having a value for permanent preservation and its own value as information as a core material for the national and cultural identify, cultural heritage is the community outcome at national level. It is a valuable cultural asset displaying the national identity and having high spiritual value as well as displaying the historicity, artistry and academic value of a nation.

Record using image which is effective in delivering information by stimulating the visual and hearing sense is used as a major method in recording cultural heritage along with photo 
and report. Visual archive is useful in delivering record effectively by having visual image and audio stimulation like onsite sounds, narrations with story and commentary and background music.

The whole process of excavating cultural assets must be recorded as a video, and must deliver the sense of realism and feeling of movement only video could have unlike reports. We know it from the fact that most researchers who initially thought visual archive would be a roadblock to the fast moving excavation site of cultural asset now keenly realized the necessity of visual archive. The necessity of visual archive will be more pressing in the future.

The context becomes important after the content when producing the visual archive, and we examined the methods to realize the context of visual archive production above.

The context is the element comprising every environment influencing users or audiences during the process of watching visual archive. Lastly, I would like to examine why this context is important.

First, we can revive the sense of realism. Having only persons, relics and events which should be included in the record and no surrounding background sound or onsite feeling of movement, we might miss the critical information which can have various onsite sounds and human voices.

Second, we can give prominence to the local cultural characteristics. The overall picture for relics, events and scenery shows the special culture of the region. Including cultural characteristics when you record cultural heritage would help you understand the cultural heritage better.

Third, we can abundantly have relevant contents. It is important to preserve and succeed the rapidly disappearing cultural heritage. We need to record the contents in details for this. Having cultural heritage itself and surrounding environment along with detailed contents will be the material for restoration and reproduction later.

Fourth, it could be the criteria at the utilization stage of various applications like multimedia production. Visual archive could be applied variously, and the material with enough information would become the basic material at the next application stage. In addition to the characteristics of archive which has a collection of information, the contextualization of visual archive is important. Contextualization makes the material have a role of information and gives more experiences.

Recognizing the importance of visual archive in archeology, archeology record is developed to another form. Various types of visual archives are expected in the future. It will be common that most ordinary people would be anxious and want to see the working process of researchers through visual archive. Video which realizes the contextualization along with more intimate communication and cooperation between archeologist and video expert will add the expertise and depth in each area.

\section{References}

[1] G. Kim, "History of Images", Thinking Tree, (2005).

[2] S. Kim and N. Kim, "Knowledge information system for developing cultural contents", Korea Contents Society Thesis Book, vol. 11, no. 12, (2011).

[3] J. Kim, "Human Computer Interaction", Ahn Graphics, (2012).

[4] Cultural Heritage Administration, "Guidebook for recording intangible cultural heritage- . Why do we record and preserve intangible cultural heritage", Cultural Heritage Administration, (2010).

[5] Cultural Heritage Administration, "Foundation direction of integrated management organization for cultural heritage record", Cultural Heritage Administration, (2012).

[6] Seojin Institute for Cultural Heritage Preservation, "Moving Plan for Seoul City Hall Relics", (2010).

[7] B. Oh and S. Kang, "Information Design Textbook", Ahn Graphics, (2008). 
[8] G. Lee, "Contents and Cultural Philosophy", Book Korea, (2009).

[8] Y. Yim and I. Bang, "Goryeo people study and videos, Visual Archive", Civilization Contents Society no. 4, (2005), pp. 122-143.

[9] S. Choi, "Study of Antiquities: Excavation Report and Visual Archive", Honam Archeology Society Honam Archeology Book, (2009).

[10] S. Choi, "Introduction to Archeology", Hakyeon Moonhwasa, (2005).

[11] Hangang Institue of Cultural Heritage, "Seoul City Hall Brief Report", (2010).

[12] Central Institute of Korean Study, "Multimedia Contents Production Manual for publishing Korea Folk Culture Electronic Encyclopedia”, Korea Folk Culture Electronic Encyclopedia, (2012).

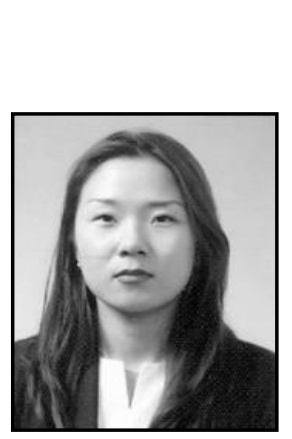

\section{Authors}

\section{Byung-Eun Park}

Byung-Eun Park is a Ph.D. candidate in the Department of Global Culture and Contents at the Hankuk University of Foreign Studies. She majored in control and measurement engineering at a university, and after she graduated, entering a documentary company. She was PD(Program Director) of Dkmedia.. She enrolled her Ph.D. course in the Department of Global Culture and Contents to find the interesting way recording cultural heritage with archive.

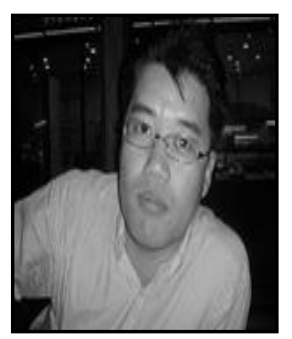

\section{Dae-Geun Lim}

Dae-Geun Lim is an Associate Professor in the Department of Global Culture and Contents at the Graduate school of the Hankuk University of Foreign Studies in Korea. He received his $\mathrm{PhD}$ in Chinese Film research from the Hankuk University of the Foreign Studies after graduating the Department of Chinese Language and Literature at the same university. His research interests include Chinese film, culture and cultural contents. He has translated and published in the research. He is a member of Forum for Chinese Film Studies, Formosa Forum, East-Asia Culture Studies and Culture Imagination Institution and exerts himself to creating a academic Sresearch community which can contribute to knowledge and practice for our society. 
International Journal of Multimedia and Ubiquitous Engineering Vol.8, No.6, (2013) 